\title{
Student Projects and Virtual Collaboration in IT Degrees: Incorporating Entrepreneurship into Study Programmes
}

\author{
Markus Helfert, Dublin City University, School of Computing, Dublin, Ireland \\ Igor Lyutak, Ivano-Frankivsk National Technical University of Oil and Gas, Department of Software of Automated \\ Systems, Ivano-Frankivsk, Ukraine \\ Howard Duncan, Dublin City University, School of Computing, Dublin, Ireland
}

\begin{abstract}
This paper describes a framework that assists the inclusion of Entrepreneurship into computing study programs. It has been developed within a European Tempus Project and is built following a process-oriented view of innovation and entrepreneurship. It outlines key activities and capabilities of entrepreneurship. An approach is presented that combines existing online tools with the traditional methodologies for creating courses on entrepreneurship. We introduce a concept -the virtual innovation space- to take the most advantages from opportunities that the Internet gives us for increasing efficiency of learning entrepreneurship for IT students. A summary of the course content on entrepreneurship that is developed and used by the project partners for their local courses is presented. We present and discuss feedback received from the project partners and describe some student projects and experiences. The work in this paper can be useful for other universities and similar projects to compare their effort and receive some justification or ideas for their initiatives.
\end{abstract}

\section{KEYWORDS}

Curriculum, Entrepreneurship, European Project Tempus, Innovation, Study Programme

\section{INTRODUCTION}

Higher education, innovation and entrepreneurship are long established as key pillars to provide various ways of engaging with enterprises. Over the last decades there has been an increased demand to include innovation and entrepreneurship into educational programs, emphasising the importance of engagement between industry and academia. However, the inclusion in curricula and educational programmes still seems to be challenging, although some successful examples illustrate how collaboration between academia and industry can be beneficial. There is no doubt that links between training, research and innovation by means of introducing advanced training in entrepreneurship and innovation capabilities are beneficial. In relation to the education domain, comparable professional standards, frameworks and curricula are important but less well established. Furthermore, although e-learning concepts seem to be particularly suited for collaboration and entrepreneurship, it appears that in e-learning programmes collaboration between academia and industry is less prominent. Furthermore, training transferable skills and creativity as part of entrepreneurship is challenging in an e-learning environment. In particular support for student projects and engagement practices are less well-developed.

This paper provides a framework and description of an open infrastructure for student projects as part of an IT entrepreneurship course that can facilitate collaboration between students and enterprises. 


\section{RELATED WORK: ENTREPRENEURSHIP, INNOVATION, AND STUDENT PROJECTS}

Many researchers have discussed innovation management and entrepreneurship as part of Information Systems (IS) and Information Technology (IT). Many have described insights into innovation processes in organisations and the role of IT (Carroll \& Helfert, 2015, Carey \& Helfert, 2015) and many tools have been suggested (Auinger et al., 2014). A large body of research is, in general, concerned with the impact of IT and the successful application of IS to support businesses becoming more innovative (Legris, 2003). Entrepreneurship and innovation are closely linked (Huff, 2013; Blundel, 2011). Recently the concept of Open Innovation has been discussed in many papers (Maccani et al. 2015; Huff, 2013; Chesbrough, 2006; Drucker, 1993). Innovation can be seen as an outcome (product) or a process (activity) or a combination of both. Process innovation has been described as any new way of developing, implementing and maintaining IS in an organisational context (Swanson, 1994). In his seminal work, Drucker focused on two aspects of innovation: the process of innovation i.e. how innovators search for opportunities and transform them into a new practice in the marketplace; and the practice of "entrepreneurship" i.e. how institutional ways and processes embed the practice of innovation into an organisation (Drucker, 1993).

A process can be described as a repeatable set of value-adding activities with a discrete beginning and a discrete ending that produces desired, predetermined, measurable outcomes. This view posits that all work is a process and all products or services are the outcomes of processes. A so-called "resource-based" view of IS/IT innovation has been popular in the literature (Feeny, 1998) and more recently a "capability-oriented" view of IS (Peppard, 2004).

Research concerning the influence on students of technical specialities in an educational program in engineering showed that there is no connection between presence of the program and a positive and significant effect on the venturing rate of the students (Militaru, 2015). Moreover, the students, with an average age of 21 years, had an opinion that entrepreneurship skills did not matter at all or that it was not closely related to the technical skills. Another investigation aimed to test an idea whether an entrepreneurship course can improve the entrepreneurial intentions, and learning efficacy of technical specialities students (Chen, 2015). The results found the entrepreneurial intentions of students have not been improved. This indicates that with the implementation of the entrepreneurship course, students should better assess their suitability to pursuing an entrepreneurial career. However, the presence of formal factors in entrepreneurial education (e.g. university's incentives to create a new business, entrepreneurial knowledge, training and skills as part of entrepreneurship education) is a base for student entrepreneurship (Urbano, 2016). Entrepreneurship education may not teach students only to initiate a start-up but to apply what they learned to their future careers. The above research indicates that introducing a generic course on entrepreneurship for students of technical specialities is mostly not effective. Moreover, research demonstrates that education should be only in terms of ethical entrepreneurship and innovative behaviour in everyday life (Ibáñez-Romero, 2016).

There is a need for further research on new approaches and for developing course and curricula for these set of students. Research towards finding approaches for increasing entrepreneurial intention during entrepreneurship education is performed by comparing results from the course for two categories of students (for business and science and engineering students) (Maresch, 2016). The principal results show that entrepreneurship education is generally effective for business students and science and engineering students. However, the entrepreneurial intention of science and engineering students is actually negatively affected by subjective norms, whereas that effect is not apparent among 
the business student sample. This paper did not give effective didactic approaches as to how to develop a course program, but it gives an understanding of what we need to research.

Research concerning evaluation of assessment methods in engineering entrepreneurship education shows a lack of effective tools that can be used (Purzer, 2016). This research shows that multiple forms of assessment instruments are needed to create a complete picture of one's entrepreneurial mind-set and competences. The tools for student assessment come usually from business courses and include such topics as business planning, design, communication, business realisation, teamwork, and leadership. These topics omit technical knowledge for engineering students. Another aspect of student assessment lies in differences between general communication skills and the skills critical to engineering entrepreneurship. The latter should be assessed with specific approaches, for instance as described in Pistrui (2012).

Increasing the effectiveness of courses can be achieved by catering for the educational needs of an individual (Sarkar, 2016), described as the knowledge and capability profile that is not given any importance in conventional education programmes (classrooms). Sarkar (2016) provides an analysis of forms of educational activities as transnational based by a university or a multinational company, online inclusive with a learning management system, a distance education online mode, and a collaborative education. Some forms of educational activities can be more effective using virtual class rooms. In addition, a successful and effective e-learning system should include personification (Kattoua, 2016) that considers personal, social, cultural, technological, organizational and environmental factors. Furthermore, building collaborative approaches between various organisations can increase effectiveness and can help to ease the career bariers (Colibaba, 2016; Bauer, 2016; Akhter, 2016). Using virtual and e-tools in this collaborative educational activity are important in order to design guidance services for students and enhance their motivation to complete their studies.

In addition, students should have a good understanding of the different stages and aspects of the entrepreneurial process. They should be able to understand how and why exposure to the main dimensions of the entrepreneurial process stimulates entrepreneurial competence development, for the individual IT entrepreneur as well as for the entrepreneurial IT team. They should also be able to assess the potential and feasibility of a new IT-based venture, with a specific focus on how to identify and make use of different entrepreneurial financing models and alternatives, and what role entrepreneurial judgment and entrepreneurial identity plays in this decision-making processes.

\section{Research Approach}

In our work to build a framework for including entrepreneurship and student projects into the curricula we follow the principles of engaged scholarship. Van de Ven (2007) describes engaged scholarship as a participative form of research for obtaining the views of key stakeholders to understand a complex problem. By exploiting differences between these viewpoints, he argues that engaged scholarship produces knowledge that is more penetrating and insightful than when researchers work alone. Engaged scholarship has a number of facets; a form of inquiry where researchers involve others and leverage their different perspectives to learn about a problem domain; a relationship involving negotiation, mutual respect, and collaboration to produce a learning community and an identity of how scholars view their relationships with their communities and their subject matter. We follow this approach in order to develop the proposed framework within the European Project. In the following we describe our framework together with some experiences. We conclude our paper by outlining some further research directions.

\section{PILLARS FOR ENTREPRENEURSHIP AND VIRTUAL COLLABORATION}

The framework was developed with consideration of training and advance key entrepreneurship skills for students. This research was developed in the context of a European Project: NEFESIE "The National Education Framework for Enhancing IT Students' Innovation and Entrepreneurship” (http:// 
tempus.nung.edu.ua). A consortium of four universities from EU countries and the five Ukrainian Universities have worked together since 2012 to build this framework. The objective of the project is to promote the synergy between academic programs, research expertise and businesses in Information Technology (IT). Critical objectives for the NEFESIE are:

- Identification of the best models and frameworks for university - company cooperation

- Development of an infrastructure that enables the sustainability of a new ecosystem of universitycompany cooperation

- Development of a web portal called Virtual Innovative Space to maintain contacts between students, companies and universities as well as to enable knowledge transfer between the actors

In addition, recent research on entrepreneurship, leadership, and innovations has turned the focus on sociological aspects, which lead us in turn to centre the framework towards the micro-level, viewing creativity, innovation, management and leadership as social processes that unfold in real time from moment to moment in and amongst a group of individuals. As the focus has shifted, we recognised the shift from traditional phenomenological and methodological boundaries to consider "on the ground" interactions of multiple participating agents who make up these processes (IszattWhite, 2011, Lundberg, 2014).

The selected research methodology of engaged scholarship seemed to be well suited for this investigation. These multiple participating agent activities are microsocial communications among actors (e.g. students, lecturers). In our research, we tried to adapt the research into our course packages to increase innovation and entrepreneurial potential in IT students. This laid the foundation for leveraging virtual collaborations among IT students and among students and IT companies.

One of the goals of the Tempus project is to develop an eco-system for enabling students', universities' and companies' continuous interaction and exchange of experiences. Based of the best experience of the universities involved in the project and results of similar international projects we have developed a set of guidelines for how to effectively organize objects in regional eco-system. These recommendations have the form of algorithms by following which a university, a student, or an IT company can organize their own resources in the best way to cooperate with others.

In order to connect all these substructures, we have proposed four steps:

- Nationwide training seminars for acceptance and understanding of the improved guidelines produced in the project.

- Awareness campaigns for students. Running an innovation competition for students.

- Organizing "The first student innovation forum in Ukraine". Create an advisory board based on a consortium of IT companies.

- Involving companies (associations of companies) as a support network for student/company contacts for good innovation.

Furthermore, for involving students, we have designed course packages for boosting innovation and start-up projects within the university environment. The courses are in-line with the establishment of a virtual collaboration platform described below. The courses have already been implemented in the study process in the Ukrainian universities. In addition, the proposed eco-system was established regionally involving five Universities from the Ukraine. The five universities have been selected due to their technical focus and the importance of their IT departments. They have established experience in cooperating with the IT industry.

Figure 1 illustrates the overall framework. The course on innovation and entrepreneurship is supported by the Virtual Innovation Space (VIS). The course chapters enclosed in ovals correspond to the course curriculum logical. The course chapters placed in the circle are supported by native 


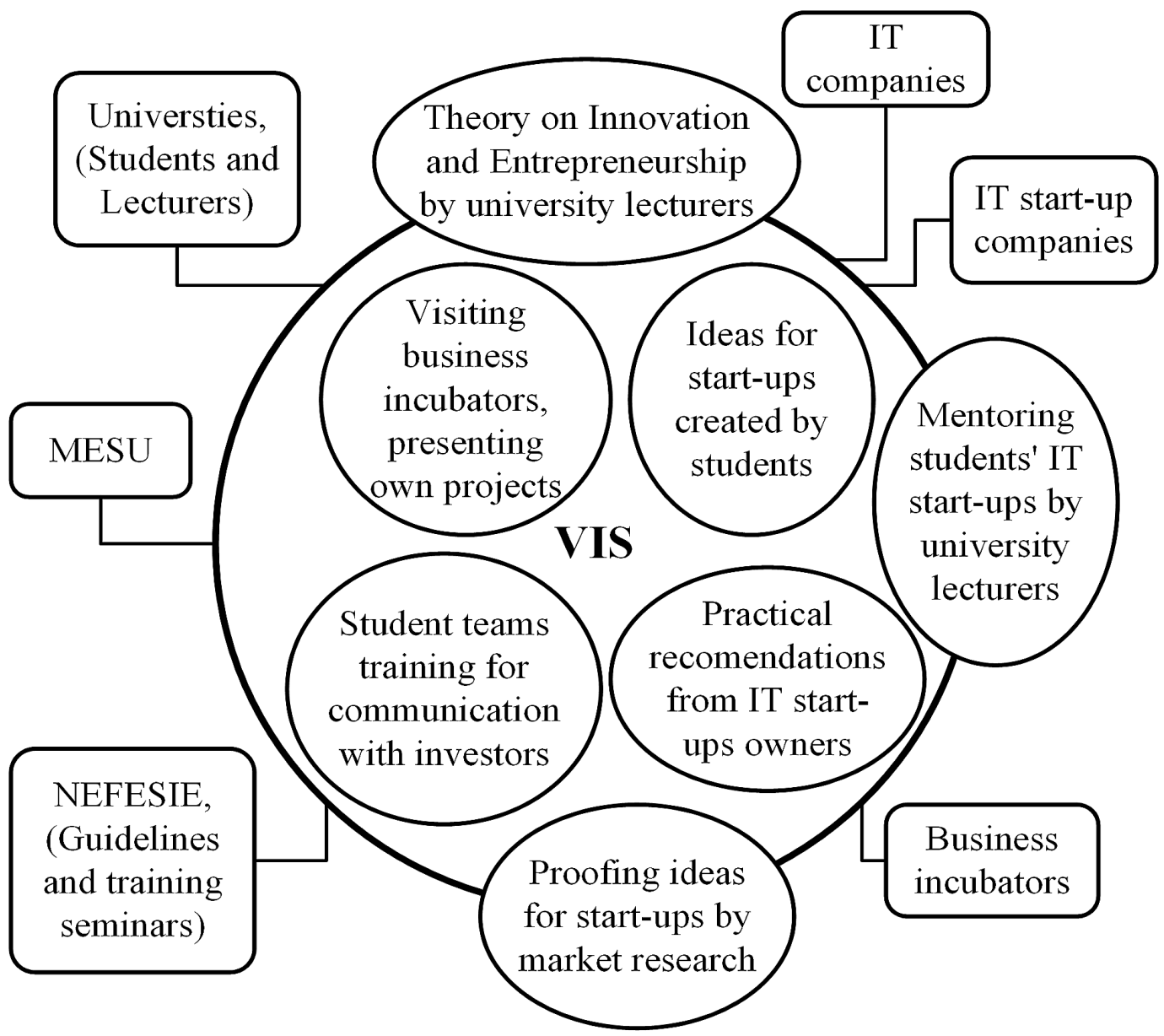

activities of the VIS. The chapters that are partly overlapping the circle can be supported by VIS partially or mediated by additional regional structures. For example, the theoretical material will be part of the VIS but lectures will be conducted by university lecturers.

\section{ENTREPRENEURSHIP MODULE}

As one example, the BSc in Enterprise Computing at Dublin City University gives students the foundation for a career in information technology for the modern business enterprise. This degree is intended to educate high-end IT professionals with knowledge of how business works and the roles of technology in the enterprise. It will teach practical skills in designing and managing information systems, and deploying them effectively and creatively. This degree provides students with an understanding of how software addresses real-world computing problems and will teach them how they can best use computing technology to help people to work together and give companies a competitive edge in the marketplace. They learn how to use and manage information technology and systems to improve and even re-design the way they do business.

The first year is devoted to gaining a strong overall competence in computing technologies, such as computers themselves, operating systems, web systems and the internet, and to acquiring 
fundamental mathematical skills. In subsequent years, by specialising in information technology, web systems or networking technologies, students are equipped with the necessary skills to work with computing technology across a broad spectrum of business enterprises. They are able to manage, improve and re-design the way businesses use computing systems. In Year Three, they will have the opportunity to spend seven months on our INTRA paid work placement programme, which integrates academic study with a closely related job. It will give them an understanding of the professional and practical business world and will help them to stand out in the graduate employment market. In final year, students study advanced modules in information systems, business strategy and management. In addition, they complete a major team-based project. Practical experience is a principal component of their learning. Throughout the four years of the degree, there are formal lectures, with a strong emphasis on the practical applications in the computer labs, tutorials, ongoing assessments and projects drawn from real-world situations.

The objective of the final year enterprise module is twofold. First, to introduce students to the theory and practice of entrepreneurship in the context of high technology venture creation. Secondly, it provides the student with a set of theoretical concepts and practical tools that can be used for understanding how IT-based innovative ideas and solutions can potentially be transformed into economic, social and/or other forms of value of which a distinct demand can be identified. The module is a combination of lectures and practical elements where students apply skills related to creativity, leadership, planning, and team management involved in initiating and developing a new business venture.

\section{Learning Outcomes}

- Analyse different stages and aspects of the entrepreneurial process

- Be able to initiate the development process of an IT-based value offer (commodity, product, service, experience or a bundle of), by doing business modelling and business planning

- Assess the potential and feasibility of a new IT-based venture

- Assess the role of universities, governments, firms and entrepreneurs in the innovation process

- Practice enhanced team working, planning, negotiation and problem solving in a high-technology product development environment

\section{INDICATIVE CONTENT AND LEARNING ACTIVITIES}

The content of the course consists of different topics related to entrepreneurial competence development and IT based value creation. We paid particular attention to innovation, creativity, and leadership as they unfold in micro-level social interactions (Lundberg, 2014; Avolio, 2016; Lundberg 2017). The execution of a team project will be the practical component of this course in which the theoretical aspects will be practiced and the practical doings will be theorized. The main focus is to gradually integrate the entrepreneurship and innovation part with development of an IT based value proposition into a coherent proposal by the end of the course, as this is key to entrepreneurial competence development within high tech sector.

Topics include:

- Foundation for High-technology Entrepreneurship.

Definitions of high- tech entrepreneurship and the Entrepreneurship process. The environmental influences affecting entrepreneurship. Ireland's high tech sector, structure and performance. Indigenous versus Overseas entrepreneurship.

- Innovation and Entrepreneurship. 
Sources of innovation; Relevance of sources to the entrepreneur; New Product Development Strategies; Technology Adoption Lifecycle. How to work and think processual in loops between creative idea generating and bringing an innovation to the market.

- Ideation

Sources of new business ideas, effective brainstorming, product benefits, idea screening, product concept development. Intellectual Property Rights. turning an opportunity into innovation, Bringing an innovation to the market,

- Entrepreneurial process and tools

The relationship of creativity and innovation to management of IT projects, How opportunity and innovation are linked within the IT domain. Business model canvases and business plans

- Financial Planning and Commercialisation

Financing requirement, financial projections and analysis, cashflow, profit and loss account, balance sheet. New product pricing. Stages and sources of financing in high tech venture, government grants, venture capital and stock market flotation.

\section{VIRTUAL INNOVATION SPACE}

In addition, to in order to facilitate virtual collaboration we have developed an online tool called a Virtual Innovation Space (VIS), aiming to facilitate the company-university-student cooperation service. In trends of increasing the role of e-learning in the Tempus project an approach to create a virtual innovation space as a website was introduced. The VIS is seen as a single network source of information, a collaborative environment, a source of mutual assistance and potential investors, e-help for more reliably improving the innovation and entrepreneurship potential of IT students and increasing the quantity of successful start-ups organized by university graduates. As the e-learning tool VIS enables IT students to: 1) enrol in innovation and entrepreneurship courses, 2) carry out their diploma project activities, 3) join in company projects, 4) present and discuss their ideas and build a team around the idea. For lecturers in universities the VIS can offer a tool for cooperation with IT companies, finding research partners, and carrying out the students' diploma projects. IT companies can see the VIS as a resource for promoting themselves and establishing connection with IT departments in universities through collaboration with lecturers. VIS provides an infrastructure and mechanisms that support interaction and knowledge transfer between students, universities and companies.

Key functionalities that this tool provides, includes:

- Competence databases, for companies, students and universities;

- Projects and assignment suggestions and support for their formation;

- Connecting people and projects, matching services;

- Collaborative space for supporting project start-ups;

- Funding mechanisms.

In the context of Ukrainian University, the VIS was a novel concept to engage with companies, students and the university to structure educational activities. The VIS facilitates and supports creating ideas from students and business concepts. It helps the preparation of a viable business and project proposal and helps to communicate and present the ideas. In conjunction with the students' contests the VIS supports the assessment of the project and ideas. Using the VIS demonstrates the improved microsocial communication among students in different universities and IT companies. VIS leverages Ukrainian student's entrepreneurial potential in order to create viable ideas and effective collaboration between companies and students. As demonstrated by some example projects from the Ukrainian students' contest and DCU, ideas cover a wide range of topics, however illustrating a common motivation seeking a market potential. That we regard as good result for Ukrainian technical students. 


\section{STUDENT PROJECTS AND VIRTUAL COLLABORATION}

The main goal of the course is to teach students to create their own start-up projects in IT and train students in entrepreneurship. During the course the students need to learn several different approaches essential for new company creation. They have to form groups to develop an IT project to a level of getting the first potential customers.

For students, reaching the goal of having customers during one or two semesters is a hard task. On the one hand, they do not have enough knowledge and have to constantly learn as usual students. On the other hand, they deal with the real market and have to obtain experience with gaps in knowledge. To solve the problem of the first steps in start-up we use the VIS. We have organized the students' innovation projects competition within the VIS. The students' projects were assessed by professionals from well-known IT companies and professors. During the first competition, the students had submitted several hundred IT innovation projects.

A few of the example projects from the competition and DCU are:

- Spectrex: The intellectual system of pulmonary survey. New unique technique for diagnosing diseases of the respiratory system will speed up and simplify the diagnostic process in medical facilities! The project aims to improve the quality of human respiratory system diagnosis by developing an expert pulmonology diagnostics system based on modern methods of analysis of macromolecular structure of moisture in exhaled air.

- An Application for Learning Foreign Words "Words with Frog": This is an effective method, based on associative memory and creating visual images. It provides quick learning of foreign words while preserving quality. The application combines a scientific approach and gaming principles for effective and rapid learning of foreign words.

- MeViCS: It offers you one of the ways to prevent slouching at home - a device «MeViCS». «MeViCS» should be applied to align the spine and preventive curvature of the spine.

- YouDrop: Architecture and software tools for building the infrastructure of distributed cloud. The idea of YouDrop is based on Peer-to-Peer (P2P) technology as a means of providing Cloud services to individuals, companies and organizations, with the view to facilitating cost-effective scalability, flexibility and efficiency and enhancing the experience of creating, organizing, publishing and sharing content.

- HotBox: HotBox(Hotspot Jukebox) is an idea for a mobile application that acts as personal jukebox interface for people in a public premises. Using this application, users can select the music playing in pubs, cafes, restaurants, bars etc. using their phone or mobile device by selecting from a music collection provided by the proprietor. It gives control to both the host and the user to select what music is being played on the premises.

- New York CitiBike Data Visualization: A web application to give users a visual representation of data obtained from www.citibikenyc.com going back to July 2013. Users will be able to view heatmaps of stations over time and to view graphs and charts of data of their choice. The application is built using Python on the Flask micro-framework using Bokeh for the visualization.

- Manage IT: Designed to help IT Managers monitor their department's service desk performance. The IT manager can input data related to service desk incidents that is then visually represented on graphs and charts. Each logged incident is assigned a RAG score based on completion success rate. This gives the IT Manager a simple way of tracking performance and identifying areas that need improvement.

- Web Based Octiv User Interface: The project is a web based user interface for controlling and retrieving information from an Octiv unit, owned and developed by Impedans Ltd. The idea behind this project is to allow remote control / data gathering from the unit, regardless of the device size or operating system. By using technologies such as JavaScript, JSON, HTML, CSS, 
Foundation framework, the website provides intuitive, responsive and impressively looking interface for the Octiv unit.

Let us show how the VIS helps a student project by an example of a "Learning Circle" that is developing by one group of five people. In the first stage students organised a group to prepare an application announced on the VIS website. In the process of preparing the application they have to describe technical and financial aspects of their idea. The application made them to be more realistic in terms of resources and values they want to produce in the project. But the process of filling in the application form is creative rather than realistic. It describes students' desires more than their capabilities.

The second stage was after assessment of the project by a jury. There were two processes during competition that had an impact on the project. The first was competition results and comments from the experts. Those comments were rather critical based on different experiences from technical to financial aspects. The second was the possibility to compare their own project with others. They could see the same mistakes and incompleteness have been made by others and are therefore more visible. We have developed a way to improve their own project. From the first two stages, they had an internal vision of changes but from the course they took direction and tools.

\section{EVALUATION AND FEEDBACK}

In practice, we have found that boosting integration processes between IT companies and a university on a regional level requires a kind of additional effort that we can call "an introduction". We do not mean that a university does not know about regional IT companies or vice versa. They do not use to their full potential all possibilities of each other's internal structures. In order to receive further feedback, we have conducted a series of interviews and surveys among key stakeholders.

In 2016 a survey involving 546 students of all years of study of Ukrainian universities was carried out. Figure 2 shows that more than $66 \%$ of respondents thought it necessary to introduce new university courses on innovation and entrepreneurship. Negative answers can be explained that students previously had a course on basics in economic science that is in the list of compulsory courses in most of the universities. Analysis of responses distribution per years of study shows a tendency that students of the third and fourth years of study are more interested in innovation and entrepreneurship courses than second-year students. This can be explained that the students of the fourth year of study have more technological competences in IT to develop software projects. The survey results allow the conclusions to be drawn that the Ukrainian students have high entrepreneurial and innovative potential and a tendency of the growing experience of practical activities. The analysis of the survey responses has shown the overwhelming importance of developing and implementing the disciplines of innovation and entrepreneurship in the University courses list for IT students in the educational and vocational training programs for "master" level.

In trends of increasing the role of e-learning in the Tempus project an approach was introduced to create VIS. Surveys among students and university staff show undeveloped innovation and entrepreneurship in both educational and research activities in universities. In summary, the feedback highlights:

- Lack of courses for IT students in innovation and entrepreneurship in the majority of Ukrainian universities

- Low level or absence of infrastructure for implementing institutional innovation and entrepreneurship policies

- Inefficient managerial capacities, (lack of well-trained management personnel) in Ukrainian universities for supporting innovation and entrepreneurship activities of IT students at the level of the modern IT market. 
Figure 2. Consideration to introduce new disciplines on innovation and entrepreneurship into the curriculum

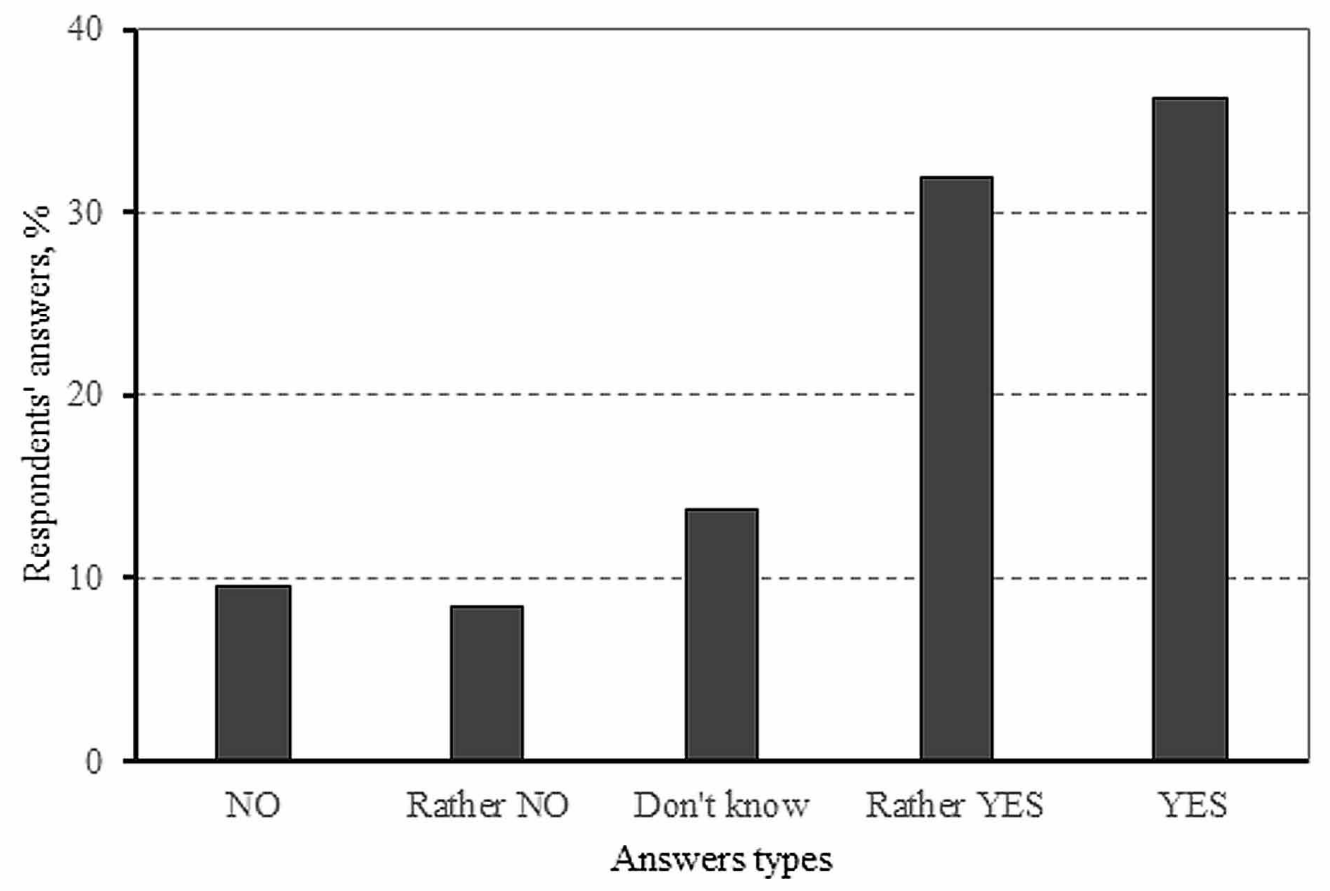

- Low level of research cooperation with IT companies and participation in international projects.

In the project to solve stated challenges we had decided not to follow a traditional approach like building innovation and entrepreneurship offices in partner universities or make a network among partner universities for implementing some changes in internal university policies.

In relation to the VIS collaboration platform, we tried to meet the challenge of boosting the VIS among potential users by conducting a contest for IT students. The contest had two nominations for IT idea and IT solution. For judging the contest, experts from IT companies and lecturers were invited. Up to now two contests had been conducted. To increase popularity each contest was conducted in a different city in the Ukraine. As a result of contest, more than 60 university and IT company representatives, 29 universities, and 18 IT companies were registered in the VIS. During the last contest, more than 200 applications were submitted by students' teams.

From a survey of lecturers that are users of the VIS we got positive and very positive responses regarding increasing knowledge and skills for implementing innovation and entrepreneurship activities among IT students.

\section{CONCLUSION}

The running of VIS project shows that modern students got into the habit using online resources for learning and easily combine them with traditional university courses. We found that at least Ukrainian IT students from the fourth-year of study and later are interested in implementing their own ideas as real start-up projects, but they do not have the necessary competences. Therefore, we can conclude that the perspective approach is to involve in traditional education online resources that can be seen as theoretical and practical tools for connecting IT students with different aspects of real market activities. 
From analysis of the students' projects we can conclude that they have a good communication among themselves. Students in a team are aware of strong and weak sides of each other. That helps them to quickly start developing technical projects by dividing the work among themselves in the most efficient way. By introducing the course on entrepreneurship for IT students we use established microsocial communication connections (Lundberg, 2014) among them for leveraging of spreading innovation ideas in their start-ups. We found that a previous experience of IT students in solving technical tasks in a team is a very good ground for start-ups. The perspective research lays in finding optimal ways to take advantage of students' technical microsocial medium (teams of students for solving technical tasks created in their social medium) to boost start-ups.

Further research should be directed towards establishing more trusted connections with big IT companies through involving them in VIS activities. 


\section{REFERENCES}

Akhter, F. (2016). Designing Information Technology Framework of Enriching E-Learning Pedagogies. TEM JOURNAL, 5(3), 379-384.

Auinger, A., Brandtner, P., Fischer, T., Helfert, M., \& Gaubinger, K. (2014). Innovation Management Support Tools - a Comparative Analysis Focusing on Open Innovation. In Proceedings of Academy of World Business (p. 12). Dubai, United Arab Emirates: Marketing \& Management Development Conference.

Avolio, B. J. (2016). Introduction: The Golden Triangle for Examining Leadership Developmental Readiness. New directions for student leadership, 2016(149), 7-14.

Bauer, P. (2016). Service Learning in Higher Education. How to Develop Social Entrepreneurship-Changemaker. Proceedings of the World Conference on Educational Media and Technology (Vol. 1, pp. 744-749).

Blundel, R., \& Lockett, N. (2011). Exploring Entrepreneurship. Oxford University Press.

Carey, K., \& Helfert M. (2015). An Interactive Assessment Instrument to Improve the Process for Mobile Service Application Innovation. In HCI in Business, LNCS (Vol. 9191, pp. 244-255). Springer.

Carroll, N., \& Helfert, M. (2015). Service capabilities within open innovation: Revisiting the applicability of capability maturity models. Journal of Enterprise Information Management, 28(2), 275-303. doi:10.1108/ JEIM-10-2013-0078

Chen, S. C., Hsiao, H. C., Chang, J. C., Chou, C. M., Chen, C. P., \& Shen, C. H. (2015). Can the entrepreneurship course improve the entrepreneurial intentions of students? The International Entrepreneurship and Management Journal, 11(3), 557-569. doi:10.1007/s11365-013-0293-0

Chesbrough, H. W. (2006). Open innovation: The new imperative for creating and profiting from technology. Harvard Business Press.

Colibaba, A., Gheorghiu, I., Colibaba, C., Colibaba, S., \& Dinu, C. E. (2016). The Power of Example. Proceedings of the International Scientific Conference eLearning and Software for Education (Vol. 3, p. 126). "Carol I" National Defence University.

Drucker, P. (1993). Innovation and Entrepreneurship. New York: Harper Business.

Feeny, D. F., \& Willcocks, L. P. (1998). Core IS capabilities for exploiting information technology. MIT Sloan Management Review, 39(3), 9.

Huff, A. S., Möslein, K. M., \& Reichwald, R. (2013). Leading open innovation. Mit Press. doi:10.7551/ mitpress/9780262018494.001.0001

Ibáñez-Romero, A., \& Zabala-Iturriagagoitia, J. M. (2016). iNNoVaNDiS: A 10-Year Experience in Entrepreneurship and Innovation Education. In Innovation and Entrepreneurship in Education (pp. 195-224). Emerald Group Publishing Limited.

Iszatt-White, M. (2011). Methodological crises and contextual solutions: An ethnomethodologically informed approach to understanding leadership. Leadership, 7(2), 119-135. doi:10.1177/1742715010394734

Kattoua, T., Al-Lozi, M., \& Alrowwad, A. A. (2016). A Review of Literature on E-Learning Systems in Higher Education. International Journal of Business Management \& Economic Research, 7(5).

Legris, P., Ingham, J., \& Collerette, P. (2003). Why do people use information technology? A critical review of the technology acceptance model. Information \& Management, 40(3), 191-204. doi:10.1016/S0378-7206(01)00143-4

Lundberg, H., Sutherland, I., Blazek, P., Penzenstadler, B., \& Habicht, H. (2014). The Emergence of Creativity, Innovation and Leadership in Micro-level Social Interactions and How to Research it.

Lundberg, H., Sutherland, I., Penzenstadler, B., Blazek, P., \& Habicht, H. (2017). "La Chispa de la Ciudad de México": Co-creation of Organizational Innovations and Its Implications for Managing Innovation. In Managing Complexity. In Managing Complexity (pp. 287-300). Springer International Publishing. 
Maccani, G., Donnellan, B., \& Helfert, M. (2015). Exploring the Factors that Influence the Diffusion of Open Data Services: an Interpretive Case Study. Proceedings of the 23rd European Conference on Information Systems (ECIS 2015), Münster, Germany.

Maresch, D., Harms, R., Kailer, N., \& Wimmer-Wurm, B. (2016). The impact of entrepreneurship education on the entrepreneurial intention of students in science and engineering versus business studies university programs. Technological Forecasting and Social Change, 104, 172-179. doi:10.1016/j.techfore.2015.11.006

Militaru, G., Pollifroni, M., \& Niculescu, C. (2015, November). The Role of Technology Entrepreneurship Education in Encouraging to Launch New Ventures. Proceedings of the Balkan Region Conference on Engineering and Business Education (Vol. 1, No. 1). National Education Framework for Enhancing IT Students' Innovation and Entrepreneurship (NEFESIE). Retrieved from http://tempus.nung.edu.ua

Peppard, J., \& Ward, J. (2004). Beyond strategic information systems: Towards an IS capability. The Journal of Strategic Information Systems, 13(2), 167-194. doi:10.1016/j.jsis.2004.02.002

Pistrui, D., Layer, J. K., \& Dietrich, S. (2012, June). Mapping the behaviors, motives and professional competencies of entrepreneurially minded engineers in theory and practice: an empirical investigation. Proceedings American Society for Engineering Education 2012 Annual Conference.

Purzer, S., Fila, N., \& Nataraja, K. (2016). Evaluation of Current Assessment Methods in Engineering Entrepreneurship Education. Advances in Engineering Education, 5(1), n1.

Sarkar, T., \& Esh, M. (2016). Require of Cooperative Learning Network Through Virtual Course and General Edification Platform for Open Education in India. The Online Journal of Distance Education and e-Learning, $4(1), 50$.

Swanson, E. B. (1994). Information systems innovation among organizations. Management Science, 40(9), 1069-1092. doi:10.1287/mnsc.40.9.1069

Urbano, D., Aparicio, S., Guerrero, M., Noguera, M., \& Torrent-Sellens, J. (2016). Institutional determinants of student employer entrepreneurs at Catalan universities. Technological Forecasting and Social Change. doi:10.1016/j.techfore.2016.06.021

Van de Ven, A. H. (2007). Engaged scholarship: A guide for organizational and social research. Oxford University Press on Demand. 